\title{
Research on the Discipline Scientification of Pedagogic Disciplines
}

\author{
Du Jianhua \\ Lecturer \\ BaiCheng Normal University in Jilin Province \\ Baicheng, 137000,China
}

Abstract- Being a highly comprehensive subject, pedagogic discipline has many branches as well as complex interdisciplines, thus getting involved into the dilemma of living. As a matter of fact, pedagogic Disciplines belong to highly professional theory, which makes it a subject that human beings make comprehensive research on the theoretical knowledge and cultural materials during the social practices. Pedagogic disciplines is discipline systems based on the disciplines and rules as well as a highly theoretically research subject. This paper will discuss the scientific definition and evaluation criterion of the pedagogic disciplines and will analyze its quality and research field.

Key words- pedagogic disciplines; scientification of the disciplines; nature; research on the problems

\section{INTRODUCTION}

As a result of the development of higher education in China and the constant perfection of the comprehensive and intensified reform on education, the reform and innovation on the scientification of pedagogic disciplines have been gradually discussed on the agenda of educational theory. This discipline has always been the focus of the scholars and teachers in educational field. Pedagogic principle is based on disciplines and rules and belongs to the basic research subject. The subject basis of education credit system is a subject with philosophical quality in the pedagogic disciplines up to now as well as a scientific theoretical system that human beings inherit its own knowledge and cultural resources. However, according to the status quo, there are many problems existing in the curriculum and teaching. This paper will analyze the scientification and evaluation criterion based on the pedagogic disciplines.

II. The scientific analysis and research field on the pedagogic disciplines

1. The nature of pedagogic disciplines

As far as the current pedagogic theory is concerned, many pedagogic disciplines do not conform to the basic disciplines of pedagogic disciplines. First of all, as for the pedagogic theory, many pedagogic theories are based on simile and metaphor rather than assumption principle. In fact, the theoretical model and research paradigm on the pedagogic disciplines are not clear enough all over the world and some of the masterpieces do not even have its own independent concepts. To be specific, the subject nature of pedagogic disciplines is integrated based on certain nature and history, which is a study on the theoretical forms. These vital ideas have strong instructive significance, which is especially true for the scientific analysis on the pedagogic disciplines from the nature.

2. Analysis by taking the pedagogic theory as discipline and course

Every subject has its reason and status of existence during meta-reflection while the education and development exists as the subject. In other words, by the structural cognition of itself and the interaction with the structural cognition of the topic, it integrated the education and development into the logical system of knowledge category, which is what we called as subject 
definition. Besides, the existence of any discipline takes certain existence as subject, which is distinguished as different parts and named after different subjects. In fact, in order to make the pedagogic disciplines scientific, it should establish a sound and complete knowledge system accordingly and make scientific explanation by concept replacement method according to certain disciplines. As is known to all, the so-called discipline is the scientific basic knowledge system of certain teaching theory organized by certain disciplines, thus being a subject that is the courses established by taking the subject as the center. On the one hand, when arranging the subject courses, the relationship between subjects and science, the relationship between disciplines and the development of the students themselves as well as the relationship between subject and pedagogic theories should be taken into consideration. What requires our special attention is that the linkage between discipline and other disciplines is the crucial factor for arranging the subject courses. It is also due to the relationship and difference between them that we can recognize there is no difference between the teaching subjects and scientific system and they all belong to knowledge system and has the right for disciplinary.

3. Analysis by taking the pedagogy as discipline and pedagogic theory on courses

Meanwhile, many textbooks based on the pedagogic disciplines and the masterpieces written by some scholars and experts are named after disciplines and the main body of discussion are between the relationship of other things and education itself, among which many are only relevant to the theoretical analysis of social productive forces, technologies, politics and economics, thus leading to the discussion on the nature of education and its laws. In fact, the educational theoretical fields have many controversies and researches on the internal rules and external laws on pedagogic and there is obvious deficiencies in the discussions and analysis on external rules and internal rules of pedagogic theories written in the textbooks and masterpieces of many scholars and experts. Generally speaking, these masterpieces and textbooks are mostly manifested based on the educational concepts and category. Only a few is based on the theoretical analysis of judgment criteria, which is also not scientific. It is especially true for the educational purposes, aims and functions, the inheritance of culture for the pedagogic disciplines and how to obtain greater development on intelligence and morality by minimum educational costs etc. These aims can be summed up as general economic problems with special quality to some extent.

\section{Basic information on the scientification of pedagogic theories in China}

In China, the pedagogic disciplines are generally defined as an independent discipline with modern connotation. In fact, as early as the late 1900s, many normal universities in China has already making experiments on disciplines of pedagogic theories since the disciplines on pedagogic theory are the actual requirements for normal universities and colleges. Therefore, being an independent subject, subjects on pedagogic theory are among the first independent subjects in design disciplines of China. Since the opening and reform in the previous century to now, the normal universities of higher education have started some relevant curriculum on pedagogic disciplines and admitted masters and doctors on certain related disciplines, during which some relevant masterpiece concerning the pedagogic theories spring up. However, they are similar to the traditional pedagogic disciplines in the courses as well as the selection of textbooks and masterpieces, which makes the orientation of pedagogic disciplines vague. The basis on internal discipline theories are in short since China has brought in the traditional pedagogic. During the introduction, little attention has been paid on the relationship between discipline and the tradition, which makes it almost the westernized pedagogic disciplines. During the 20 century when China made great efforts to develop education, only the normal universities directly used the pedagogic disciplines which makes the pedagogic disciplines actually a demonstration campus subject and mixed it up incorrectly. Therefore, during the actual development 
process of pedagogic, it is usually connected with the nature of pedagogic disciplines. Seen from the actual status quo on education, it is generally the combination and paraphrase on the knowledge and the theories in the textbook generally follow the theoretical knowledge of other countries. However, this situation has changed to a certain degree in 1990s but China has still been in the primary stage on the research of this aspect and there is no overall breakthrough yet.

\section{Research on the scientification of the disciplines of pedagogic theories}

In order to promote the development on the scientification of pedagogic subjects, the focus should be on the theories, concepts and thoughts and the theories, thoughts and concepts of pedagogic disciplines should be further clarified. The definition of the theories should not only clear but also should take corresponding philosophical ideas as the theoretical basis. To realize the scientification of pedagogic should guarantee the systematization of the disciplines and enlargement of the theoretical extension and the deepening on the theoretical connotation. It is necessary to increase the system in concepts so as to ensure the commonality and popularity. Every scholar can put forward his own insight on the educational concepts and have his own opinion on education thoughts. But only a few experts or educator of pedagogic disciplines can construct the theoretical thoughts. Actually, some experts and educators have already taken the research on pedagogy as a science and make survey on it as a career.

Some people with insights and educators regard education as an activity that human society inherits the knowledge and cultural resources. Therefore, it is necessary to establish a scientific and strict general and scientific pedagogic discipline. The philosophical basis of this theory is that human itself is in the natural practices, namely "practice is the sole criterion for testing the truth of the theories".

Discussion from the scientification of pedagogic theories, the reform on the permissible courses and grades on pedagogic theories in China are critical from many aspects and it is a demonstration on the scientific education evaluation and the scientificity. Under such situation, scientific spirit is a theory on the nature of science and it manifests the seeking truths from facts and the rationality. Therefore, according to such principle, the evaluation on education should be based on reality and rationality is the real science. In fact, this deduction is incorrect since the existence of scientific spirit is indeed good but such spirit should have scientific conclusion and behaviors. Besides, the theoretical property of the theoretical theories is also the existence for thoughts rather than being owned by scientific thoughts. The criticism on the education should combine with the mechanism with the judgment as well as the integration of value judgment.

On the other hand, some research on pedagogy is put forward by physics terminology which proposes that the quality of the students refers to the teaching quantity of the state on the pedagogic disciplines and the quality of education reflects the quantity process. In fact, this view is also incorrect. In the actual teaching process, the teaching quality is the process amount which is reflected in the variation on the quality of the students and exists since the very beginning of education. The so-called quantity of state refers to the difference between the students before taught and after taught. The process amount is the increasing amount of quality by scientific method. Basically speaking, these theoretical opinions are mostly denial of the previous practical educational assessment methods. Actually, the international organization for standardization has illustrated the definition on the quality which refers to that the processes, systems and products all have their inherent quality so that the quality of education should be measured by the quality of the students.

At last, the scientification on the pedagogical disciplines should be explained in the articles of current scholars. Actually, the scientific quality of pedagogic disciplines should be clarified in concepts, thoughts and theories. The problems in scientification of pedagogic subjects are the essential paradox in education. This problem is 
caused by the limited life of human beings as well as the limitless of knowledge and cultural resources. Due to the special quality of educational inheritance, the education science can make a great difference and can integrate and select valuable knowledge and culture from the limitless knowledge and culture, which make it helpful for the teaching. The above mentioned are the layers referred to in course design and arrangement. When the courses are arranged, a teaching method should be established. In order to realize maximum knowledge aims with minimum costs during the pedagogic teaching process, perfect course arrangement and effective teaching methods are necessary factors for learning theories. Therefore, the scientification of the pedagogic disciplines is actually the integration of courses, teaching and learning.

\section{Conclusions}

In a word, as a professional principle subject, the scientific research on the pedagogical discipline is of vital significance. The development of scientification is quite necessary for the pedagogical subject. Since education is the inheritance process for knowledge, it leads to many basic concepts of the disciplines, such as the development of the subject cognition, construction on the subject curses, teaching and exams on the subjects etc. By the definition and analysis on the logic of pedagogical theories, this paper conclude and systemize the status quo, development and existing problems during the scientification of pedagogic disciplines, thus proving the importance for realizing the scientification of pedagogical disciplines.

\section{References:}

[1] Qi Mei. Research on the scientification of Pedagogic Disciplines [D].Northeast Normal University, 2009.

[2] Gao Peng. On the scientification of Pedagogic knowledge[D].Northeast Normal University,2014.

[3] Qi Mei. Analysis on the Basic Concept of Pedagogic Disciplines[J]. Education Science, 2010,02:13-15.

[4]Qi Mei \& Liu Haiming. On the Scientific Quality and Basic problems of Pedagogic Disciplines [J]. Educational Research,2010,02:28-32.

[5] Kuai Xueting. Research on the scientification of Pedagogic disciplines[J]. Tourism Overview,2013,08:217.

[6] Wang Yanmin. On the Metholodogy Basis of Pedagogy[D].Northeast Normal University,2010.

[7] Lao Kaisheng,Shi Zhongying \& Zhu Xinmei. On the Pedagogical Discipline that is in solid cooperation and eager in innovation $[\mathrm{J}]$. Journal of Beijing Normal University(Issue of Humanity and Social Science),2012,05:144-152. 